\title{
Hemispheric processing in differential classical eyelid conditioning
}

\author{
WILLIAM A. BENISH and DAVID A. GRANT \\ University of Wisconsin, Madison, Wisconsin 53706
}

\begin{abstract}
During both stages of a two-stage differential classical eyelid conditioning study, visual CSs were projected randomly either to the right or to the left of a central fixation point in order to investigate a hypothesis relating the differences between $\mathrm{V}$-form and $\mathrm{C}$-form responders to cerebral hemispheric processing asymmetries. Failing to extend the findings of an earlier investigation, the present set of results provided little evidence in support of the hemispheric point of view.
\end{abstract}

A measure of order has been contributed to the differential conditioning literature by the partitioning of subjects into $\mathrm{V}$-form and $\mathrm{C}$-form responders (Vs and $\mathrm{Cs}$, respectively). The nature of this subject variable is considered in another article (Benish \& Grant, 1980a) and is treated more thoroughly by Grant $(1968,1972)$. One of the more intriguing hypotheses regarding the nature of the difference between Vs and Cs is attributable to Saltz (1973). Within the context of cerebral hemispheric processing asymmetries, he suggested that "The C-form . . . may bypass the left hemisphere, while the V-form may involve left hemisphere mediation" (Saltz, 1973, p. 24). Given that Vs are more influenced by the semantic aspects of verbal stimuli than are Cs, this hypothesis is reasonable in light of the evidence that the left cerebral hemisphere of right-handed adults is specialized for linguistic processing (e.g., Cohen, 1972; Diamond, 1972; Gazzaniga, 1970). Moreover, just as Vs have been found to have a positive response bias relative to Cs, an excitatory bias has been associated with the left hemisphere (e.g., Cohen, 1973).

Saltz's (1973) hypothesis received support from several observations reported by Hellige (1975), observations that are consistent with the assumption that Cs should perform more like Vs when conditioned stimuli (CSs) are presented briefly in the right visual field (RVF) than when CSs are presented in the left visual field (LVF). It is argued that a RVF stimulus presentation will facilitate left-hemisphere mediation, since the cerebral hemispheres initially receive information from the contralateral visual fields. With the word "blink" as the reinforced CS (CS+) and the words "don't blink" as the unreinforced CS (CS-), Hellige found that discrimination performance of Cs was superior when the stimuli were projected to the RVF and that conditioned response (CR) latency tended to be shorter to a RVF presentation. Furthermore, the topography of the CR given to RVF stimuli attenuated the air-puff unconditioned stimulus (UCS) more among Cs who received BLINK+ and DON'T BLINK - than among Cs for whom these contingencies were reversed. Finally, averaged over both reinforcement contingency conditions, more responses were given to RVF stimuli than to LVF stimuli. Although each of these results was statistically significant, it is difficult to determine the number of other possible findings that would also have been consistent with Saltz's suggestion and, thereby, evaluate the hypothesis critically. It was therefore decided that Hellige's method of randomly and briefly presenting the CSs in the RVF and LVF should be adopted in the present study. This investigation is essentially an addendum to the work discussed in Benish and Grant (1980a, 1980b). Methodological details can be obtained by referring to those articles.

\section{RESULTS AND DISCUSSION}

The present results were compared with each of Hellige's (1975) statistically significant findings that were in agreement with the assumption that Cs will perform more like Vs when given a RVF stimulus presentation. Only one of Hellige's findings was replicated: During both stages of the experiment, Cs emitted shorter latency $\mathrm{CRs}$ to $\mathrm{CS}+$ with a RVF stimulus presentation than with a LVF presentation (mean Stage 1 difference $=37 \mathrm{msec}$; mean Stage 2 difference $=11 \mathrm{msec}$ ). Neither of the differences was significant. In fact, no statistically significant findings that could be interpreted as providing support for Saltz's (1973) hypothesis were uncovered.

The absence of such effects suggests that if V-C differences actually are related to information asymmetries between the cerebral hemispheres, then this relationship may be so subtle as to elude verification with an eyelid conditioning procedure. In deference to Saltz's (1973) hypothesis, however, it is important to emphasize that the stimuli employed by Hellige (1975) and the present stimulus set are more than nominally different. Furthermore, while examining eyelid topography in differential interstimulus interval conditioning, Kadlac and Grant (1977) identified a significant interaction among the V-C dimension, trial block, and field of CS presentation that also can be explained by Saltz's suggestion. 


\section{REFERENCES}

Benish, W. A., \& Grant, D. A. Intrastimulus conflict in differential classical eyelid conditioning. Bulletin of the Psychonomic Society, 1980, 15, 428-430. (a)

Benish, W. A., \& Grant, D. A. Subject awareness in differential classical eyelid conditioning. Bulletin of the Psychonomic Society, 1980, 15, 431-432. (b)

COHEN, G. Hemispheric differences in a letter classification task. Perception \& Psychophysics, 1972, 11, 139-142.

COHEN, G. Hemispheric differences in serial versus parallel processing. Journal of Experimental Psychology, 1973, 97, 349-356.

DiAmond, S. The double brain. Baltimore: Williams \& Wilkins, 1972.

GAZZANIGA, M. S. The bisected brain. New York: AppletonCentury-Crofts, 1970.

Grant, D. A. Adding communication to the signalling properties of the CS in classical conditioning. Journal of General Psychology, 1968, 77, 295-300.
Grant, D. A. A preliminary model for processing information conveyed by verbal conditioned stimuli in classical differential conditioning. In A. H. Black \& W. F. Prokasy (Eds.), Classical conditioning II: Current theory and research. New York: Appleton-Century-Crofts, 1972.

Hellige, J. B. Hemispheric processing differences revealed by differential conditioning and reaction time performance. Journal of Experimental Psychology: General, 1975, 104, 309-326.

KADlAC, J. A., \& GRANT, D. A. Eyelid response topography in differential interstimulus interval conditioning. Journal of Experimental Psychology: Human Learning and Memory, 1977, 3, 345-355.

SALTZ, E. Higher mental processes as the bases for the laws of conditioning. In F. J. McGuigan \& D. B. Lumsden (Eds.), Contemporary approaches to conditioning and learning. Washington, D.C: Winston, 1973.

(Received for publication April 24, 1980.) 